\title{
RNase L Variants Do Not Appear to Impact on Clinical Features of Sporadic Prostate Cancer Patients ${ }^{*}$
}

\author{
Frank T. D’Arcy ${ }^{1,2}$, Ruth Foley ${ }^{1}$, Thomas H. Lynch ${ }^{2}$ \\ ${ }^{1}$ Institute of Molecular Medicine, Trinity College, Dublin, Ireland \\ ${ }^{2}$ Department of Urology, St. James Hospital, Dublin, Ireland \\ Email: darcyft@hotmail.com
}

Received November 4, 2013; revised November 23, 2013; accepted November 28, 2013

Copyright (C) 2013 Frank T. D’Arcy et al. This is an open access article distributed under the Creative Commons Attribution License, which permits unrestricted use, distribution, and reproduction in any medium, provided the original work is properly cited.

\begin{abstract}
Introduction: Prostate cancer is the most common non-cutaneous male cancers, contributing to significant mortality rates globally. Mutations of RNase L, an enzyme involved in inflammatory and immunological pathways, have been speculated to predispose to cancer. This study assesses three different mutations of the RNase L gene in Irish prostate cancer patients, including one linked with general cancer susceptibility never investigated before in prostate cancer (rs3738579), and reports on links with aggressive cancer. Methods: 134 patients had their RNase L mutation status determined by polymerase chain reaction (PCR) of serum DNA. Complementary clinical details for each patient are statistically analysed. Results: No link to age of diagnosis, high grade disease or prostate specific antigen (PSA) level at diagnosis was demonstrated with any of the studied single nucleotide polymorphisms (SNP). The SNP variation was consistent with that of published international series. Conclusion: SNP genotypic frequencies in Ireland are consistent with international findings. The studied RNase L mutations including rs3738579 do not appear to have a significant impact on our patient population.
\end{abstract}

Keywords: RNase L; $\mathrm{R}_{462} \mathrm{Q}$; $\mathrm{D}_{541} \mathrm{E}$; Prostate Cancer

\section{Introduction}

RNase $\mathrm{L}$ is a gene found on the hereditary prostate cancer (HPC) locus of chromosome 1 that codes for a latent endoribonuclease. This enzyme participates in an interferon inducible RNA decay pathway that has a role in inflammation and cellular immunity against viral infection. Sustained activation will lead to apoptosis. The gene is 741 amino acids long with 8 exons and is roughly 13 kilobases. It is converted from an inactive monomeric form to a potent dimeric structure by the action of a series of 2 ' to 5' linked oligodenylates, commonly known as 2 5 A.

RNase L has been a candidate gene for prostate cancer researchers for a number of years and many variants including $\mathrm{R}_{462} \mathrm{Q}$ [1], $\mathrm{E}_{265} \mathrm{X}$ [1], $\mathrm{M}_{1} \mathrm{I}$ [2] and 471 $\triangle \mathrm{AAAG}$ [3] have been described.

The $\mathrm{R}_{462} \mathrm{Q}$ RNase L mis-sense mutation (rs486927) arises when a substitution of the "G" to "A" base along exon 1 at mRNA position 1552 gives an amino acid

*All funding for described work came via Trinity College Dublin and The Irish Cancer Society. change of argenine to glutamine at amino acid position 462. The consequence of this is a variant of the gene that produces an enzyme functioning at a third of the wildtype enzyme's efficiency [4]. It has been of interest to researchers since it was linked to prostate cancer in 2002 [2]. Subsequent studies have been mixed with some showing a link with this variant and familial prostate cancer $[5,6]$, whilst others have not [7]. A meta-analysis of 7 papers has failed to show a significant link between this mutation and prostate cancer regardless of ethnicity or family history [8].

$\mathrm{D}_{541} \mathrm{E}$ (rs627928) comes about following a substitution of the "T" base at mRNA position 1790 with "G", causing a change in the protein at amino acid position 541 from aspartate to glutamic acid. This area of the gene codes for a region within the protein kinase domain of the enzyme, an area with an important role in dimerization of the protein into its active state. Despite the mutation, this enzyme has comparable catalytic activity with the wildtype variant [4]. Its significance is the source of some debate within the literature. Studies have linked 
this change to an increased risk of familial prostate cancer [7] and sporadic, metastatic disease [9], but in a Japanese study [10] the wildtype variant was actually linked to an increased risk of familial prostate cancer. Other investigators have found no significant associations with it $[1,5,11]$.

An undescribed mutation (rs3738579) located in the 5' untranscribed region ( $5^{\prime}$-UTR) has been identified as a general indicator of increased cancer susceptibility [12]. The exact role of this variant on expression is unclear but mutations are seen disproportionally in cervical as well as head and neck squamous cell cancers.

Work in the fields of cervical cancer (human papillomavirus) [13], gastric cancer (helicobacter pylori) [14], B-cell lymphomas (Epstein-Barr virus) [15] and osteogenic sarcomas (chronic osteomyelitis) [16] have all found definite links between chronic infection and neoplasia. Whilst no such links have yet been established in prostate cancer, there are inconsistent reports in the literature of positive associations of the disease with sexually transmitted infections (STIs) [17-19], and one study finding men with 25 or more sexual partners being 2.8 times more likely to be diagnosed with prostate cancer than a man with 5 or less partners [20]. If inflammation or viral infection plays a role in prostate cancer development, it is speculated that polymorphisms in genes involved in the inflammatory and infectious disease pathways like RNase L could be important.

This study aims to sequence RNase L single nucleotide polymorphisms (SNPs) in men with known cases of sporadic prostate cancer and correlate to the clinical aspects of the cancer.

\section{Methods and Materials}

Patient samples were obtained from the Prostate Cancer Research Consortium (PCRC) bio-repository. This is a collaboration of three University institutions affiliated with five major hospitals. Complementary clinical details relating to each patient are also logged into a password protected, secure database. All volunteers were pre-operative radical prostatectomy patients with localised prostate cancer, enrolled with full consent in line with ethical advice. All cases of prostate cancer analysed were sporadic.
Using the database of known SNPs published online at the National Centre for Biotechnology Information (NCBI), the sequence of code surrounding the SNPs of interest were obtained.

Primers were designed using Primer Express (Applied Biosystems, USA). Details of the actual sequence of interest and the primer set are given in Table 1. Primers were supplied by MWG and were purchased at 0.01 $\mu \mathrm{mol}$ scale, HPS purification.

DNA was extracted from peripheral blood DNA by the Autopure automated system (Qiagen, USA) which uses puregene chemistry. The product was purified (Qiaquick PCR purification kit from Qiagen, USA) and sequencing reactions with a fluorescent dye terminator (BigDye v3.1, $A B I)$ were performed. Results were interpreted with $\mathrm{Se}$ quencing Analysis v5.1 from Applied Biosystems.

Polymerase chain reaction (PCR) was carried out with the product initially being exposed to $94^{\circ} \mathrm{C}$ for thirty seconds, followed by 35 cycles where the temperature alternated from $94^{\circ} \mathrm{C}$ for 30 more seconds, then $\left[53.1^{\circ} \mathrm{C}\right.$ $\left(\mathrm{R}_{462} \mathrm{Q}\right) / 53^{\circ} \mathrm{C}\left(\mathrm{D}_{541} \mathrm{E}\right) / 55^{\circ} \mathrm{C}\left(5^{\prime}\right.$-UTR $\left.)\right]$ for 30 seconds followed by a minute at $72^{\circ} \mathrm{C}$. The reaction culminated in 30 minutes exposure to $72^{\circ} \mathrm{C}$.

\section{Results}

Table 2 illustrates the frequencies of each RNase L SNP studied in the prostate cancer population. These figures are in keeping with those published on the NCBI database.

$$
\underline{\mathrm{R}}_{462} \underline{\mathrm{Q}}
$$

$9 \%$ of patients had the homozygous AA genotype $\left(\mathrm{R}_{462} \mathrm{Q}\right)$, which corresponds to the less efficient variant of the RNase L enzyme, while 52.2\% were heterozygous for this SNP. Table 3 outlines $\mathrm{R}_{462} \mathrm{Q}$ status versus histological disease aggression. On initial inspection it would appear that a disproportionate amount of men with the AA (i.e. the $\mathrm{R}_{462} \mathrm{Q}$ ) genotype have tumours that are of Gleason score 7 or greater (7 out of 11). This association, whilst a trend did not demonstrate statistical significance $(p=0.258)$. No association was seen between this SNP and either percentage gland involvement by tumour $(\mathrm{p}=$ $0.57)$ or number of affected first-degree relatives $(\mathrm{p}=$ 0.69 ). Furthermore, anova 1-way $\mathrm{p}$ values for age and prostate specific antigen (PSA) levels at diagnosis also failed to demonstrate any statistical significance $(\mathrm{p}=$

Table 1. Description of primers selected for each SNP studied.

\begin{tabular}{ccccc}
\hline DbSNP ID & Base & Amino acid & Primer & Sequence \\
\hline \multirow{2}{*}{ rs486907 } & G/A & R462Q & Forward & 5'-TGGAAGCGTGTTTGGATGTG-3' \\
& & Reverse & 5'-TGCAGATCCTGGTGGGTGTA -3' \\
rs627928 & T/G & D541E & Forward & 5'-TTGATTTATGGCTTTTGTGCAGG-3' \\
& & & Reverse & 5'-TGAGGTCCTTAGTTTCCTCATCT-3' \\
rs3738579 & C/T & - & Forward & 5'-GTGGAAT GTCAGAAGAC TGAGAAC-3' \\
& & & & 5'-AATGCCACCTGCTACCACTT-3'
\end{tabular}


Table 2. Summary of sequencing results for each SNP in men with prostate cancer.

\begin{tabular}{ccc}
\hline SNP & Genotype & Frequency (\%) \\
\hline \multirow{2}{*}{$\mathrm{R}_{462} \mathrm{Q}$} & AA (Mutation) & $12 / 134(9 \%)$ \\
& AG & $70 / 134(52.2 \%)$ \\
& GG (Wildtype) & $52 / 134(38.8 \%)$ \\
$\mathrm{D}_{541} \mathrm{E}$ & GG (Mutation) & $35 / 91(38.5 \%)$ \\
& GT & $38 / 91(41.7 \%)$ \\
& TT (Wildtype) & $18 / 91(19.8 \%)$ \\
5 '-UTR (rs3738579) & CC (Mutation) & $18 / 136(13.2 \%)$ \\
& CT & $55 / 136(40.4 \%)$ \\
& TT (Wildtype) & $63 / 136(46.4 \%)$ \\
\hline
\end{tabular}

Table 3. Gleason score and SNP status at the exon $1 / R_{462} Q$ SNP.

\begin{tabular}{cccccc}
\hline Gleason Score & AA & AG & GG & Total numbers & P value \\
\hline $4-6$ & 4 & 39 & 23 & 66 & \\
$7-9$ & 7 & 26 & 23 & 56 & \\
Total & 11 & 65 & 46 & 122 & $\mathrm{p}=0.258$ \\
\hline
\end{tabular}

0.60 and 0.44 respectively).

\section{$\underline{\mathrm{D}}_{541} \underline{\mathrm{E}}$}

$38.5 \%$ of prostate cancer patients in the study were shown to carry the $\mathrm{D}_{541} \mathrm{E}$ mutation. Analysis of complementary clinical data revealed no association with either percentage gland involvement $(\mathrm{p}=0.58)$, number of first-degree relatives affected $(p=0.058)$ or age at diagnosis $(p=0.68)$. Analysis of PSA at diagnosis (on Table 4) revealed that men with the mutation had a much higher PSA at diagnosis however this fell just short of statistical significance $(\mathrm{p}=0.06)$.

Analysis of Gleason score of tumour and SNP status failed to show any statistically significant association ( $p$ $=0.68$ ).

\section{5'-UTR}

Statistical analysis of Gleason score $(p=0.24)$, percentage gland involvement $(\mathrm{p}=0.5)$, family history $(\mathrm{p}=$ $0.49)$, age $(\mathrm{p}=0.29)$ or PSA at diagnosis $(\mathrm{p}=0.77)$ failed to reveal any association with this SNP (see Table $5)$.

\section{Discussion and Review of the Literature}

To our knowledge this is the first study of the RNase L SNP rs3738579 in the context of prostate cancer and also adds to the debate about the significance of $\mathrm{D}_{541} \mathrm{E}$ and $\mathrm{R}_{462} \mathrm{Q}$.

There are a number of studies in the literature examining prostate cancer and the $\mathrm{R}_{462} \mathrm{Q}$ mutation. The results of these are summarised in Table 6 and a comparison of the frequency that the mutation is detected across these series are displayed in the Forest plot given in Figure 1. This shows our findings to be consistent with internationally published series.
Table 4. Breakdown of PSA values (given as $\mathrm{ng} / \mathrm{ml}$ ) versus genotype at $D_{541} E$ SNP.

\begin{tabular}{cccc}
\hline Genotype & Mean $\pm \mathrm{SD}$ & Median & Anova 1-way $\mathrm{p}$ value \\
\hline $\mathrm{GG}\left(\mathrm{D}_{541} \mathrm{E}\right)$ & $8.42 \pm 3.13$ & 8.25 & \\
$\mathrm{GT}$ & $7.08 \pm 3.26$ & 6.25 & 0.0634 \\
$\mathrm{TT}$ & $6.84 \pm 2.07$ & 6.6 & \\
\hline
\end{tabular}

Table 5. Analysis of low and high grade tumours versus 5'-UTR locus SNP status.

\begin{tabular}{cccccc}
\hline Gleason score & CC & CT & TT & Total numbers & p value \\
\hline $4-6$ & 8 & 29 & 29 & 66 & \\
$7-9$ & 8 & 22 & 26 & 56 & \\
Total & 16 & 51 & 55 & 122 & 0.24 \\
\hline
\end{tabular}

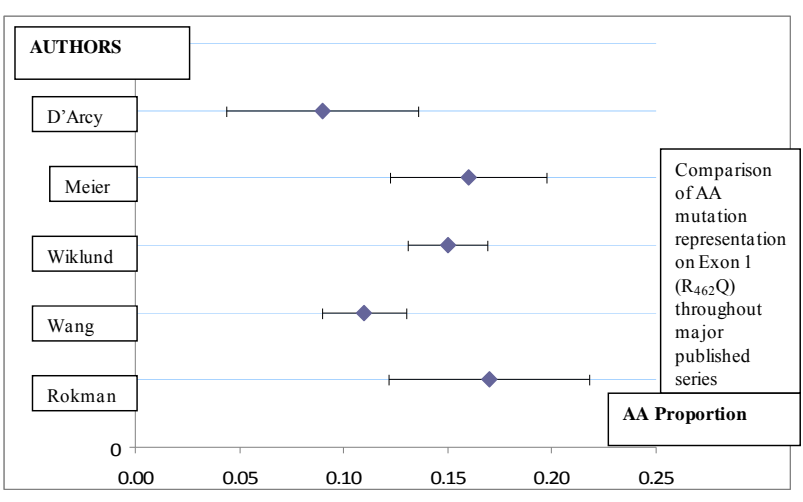

Figure 1. Expression of mutated form of Exon 1, AA $\left(R_{462} Q\right)$, as a proportion of total numbers examined for all major studies, expressed on a Forest plot. Y-axis has study's author's name whilst $\mathrm{X}$-axis contains proportion of AA genotype given with $95 \%$ confidence limits.

$\mathrm{D}_{541} \mathrm{E}$ mutation has been the focus of multiple studies. We fail to demonstrate a significant clinical association with this mutation. Results summary and comparison of frequency of mutation are given in Table 7 and Figure 2 respectively.

Rokman's study focused on 492 patients with prostate cancer, 47 of whom reported a positive family history. They were consecutive cases diagnosed at the University Hospital, Tampere, Finland, over a three-year period. This population would have differed from the one we are reporting on by including men with both organ confined and metastatic disease. Control samples came from 566 healthy male blood donors. This study failed to show any significant difference in $\mathrm{D}_{541} \mathrm{E}$ status between prostate cancer, BPH and normal control groups and concluded that this mutation doesn't have an important role in prostate cancer within their population. It did however demonstrate an association between $\mathrm{R}_{462} \mathrm{Q}$ status and hereditary prostate cancer.

Wang's study came from Minnesota in the United States and included a total of 825 patients with prostate 
Table 6. Comparison of results of analysis of $\mathbf{R}_{462} Q$ mutation (“AA" genotype) throughout different studies within the literature.

\begin{tabular}{ccccccc}
\hline Study Author & Population & Patient group & AA (Mut) Genotype & AG Genotype & GG Genotype & Total \\
\hline \multirow{2}{*}{ Rokman [1] } & \multirow{2}{*}{ Finnish } & Prostate cancer & $39(16.7 \%)$ & $106(45.5 \%)$ & $88(37.8 \%)$ & 233 \\
& & Control & $23(13.1 \%)$ & $84(47.7 \%)$ & $69(39.2 \%)$ & 176 \\
Wang [5] & \multirow{2}{*}{ Hispanic and White. USA } & Prostate cancer & $102(11.1 \%)$ & $427(46.5 \%)$ & $389(42.4 \%)$ & 918 \\
& & Control & $67(13.5 \%)$ & $233(47.3 \%)$ & $193(39.1 \%)$ & 493 \\
Wiklund [7] & \multirow{2}{*}{ Swedish } & Prostate cancer & $247(15.2 \%)$ & $778(48.0 \%)$ & $597(36.8 \%)$ & 1622 \\
& & Control & $115(14.4 \%)$ & $384(48.2 \%)$ & $297(37.4 \%)$ & 796 \\
Maier [11] & \multirow{2}{*}{ German } & Prostate cancer & $59(16.3 \%)$ & $171(47.1 \%)$ & $133(36.6 \%)$ & 363 \\
D'Arcy & \multirow{2}{*}{} & Control & $37(17.9 \%)$ & $97(46.9 \%)$ & $73(35.2 \%)$ & 207 \\
\hline
\end{tabular}

Table 7. Comparison of results of analysis of $D_{541} E$ mutation (“GG” genotype) throughout different studies within the literature.

\begin{tabular}{|c|c|c|c|c|c|c|}
\hline Study Author & Population & Patient group & GG (Mut) Genotype & GT Genotype & TT Genotype & Total \\
\hline \multirow{2}{*}{ Rokman [1] } & \multirow{2}{*}{ Finnish } & Prostate cancer & $78(33.5 \%)$ & $126(54.1 \%)$ & $29(12.4 \%)$ & 233 \\
\hline & & Control & $56(31.8 \%)$ & $91(51.7 \%)$ & $29(16.5 \%)$ & 176 \\
\hline \multirow{2}{*}{ Wang [5] } & \multirow{2}{*}{ Hispanic and White. USA } & Prostate cancer & $181(19.5 \%)$ & $476(51.2 \%)$ & $272(29.3 \%)$ & 929 \\
\hline & & Control & $107(21.1 \%)$ & $228(44.9 \%)$ & $173(34.0 \%)$ & 508 \\
\hline \multirow{2}{*}{ Wiklund [7] } & \multirow{2}{*}{ Swedish } & Prostate cancer & $462(33.9 \%)$ & $668(49.0 \%)$ & $233(17.1 \%)$ & 1363 \\
\hline & & Control & $257(32.5 \%)$ & $372(47.0 \%)$ & $162(20.5 \%)$ & 791 \\
\hline \multirow{2}{*}{ Maier [11] } & \multirow{2}{*}{ German } & Prostate cancer & $125(34.4 \%)$ & $176(48.5 \%)$ & $62(17.1 \%)$ & 363 \\
\hline & & Control & $69(33.3 \%)$ & $97(46.9 \%)$ & $41(19.8 \%)$ & 207 \\
\hline \multirow{2}{*}{ Noonan-Wheeler [9] } & \multirow{2}{*}{ European-Americans } & Prostate cancer & $55(36.7 \%)$ & $73(48.7 \%)$ & $22(14.6 \%)$ & 150 \\
\hline & & Control & $44(25.7 \%)$ & $94(55.0 \%)$ & $33(19.3 \%)$ & 171 \\
\hline \multirow{2}{*}{ Nakazato [10] } & \multirow{2}{*}{ Japanese } & Prostate cancer & $51(50.5 \%)$ & $32(31.7 \%)$ & $18(17.8 \%)$ & 101 \\
\hline & & Control & $59(56.2 \%)$ & $43(40.9 \%)$ & $3(2.9 \%)$ & 105 \\
\hline D'Arcy & Irish & Prostate cancer & $35(38.5 \%)$ & $38(41.7 \%)$ & $18(19.8 \%)$ & 91 \\
\hline
\end{tabular}

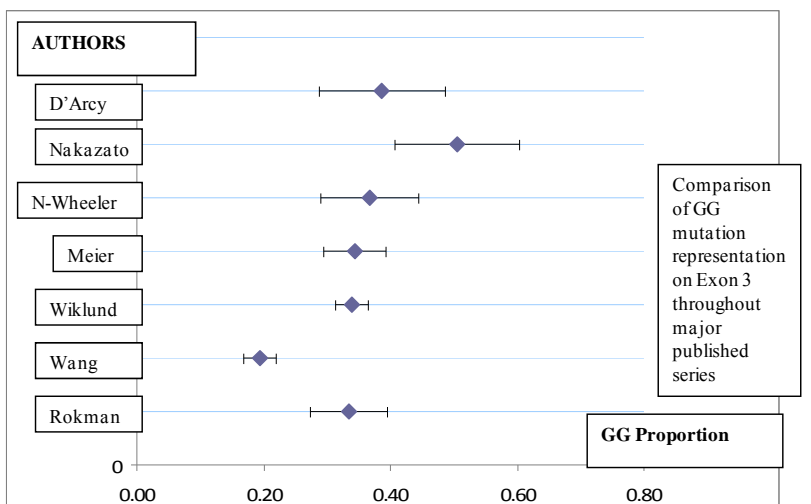

Figure 2. Expression of mutated form of Exon 3, GG $\left(D_{541} E\right)$, as a proportion of total numbers examined for all major studies, expressed on a Forest plot. Y-axis has study's author's name whilst $X$-axis contains proportion of GG genotype given with $95 \%$ confidence limits.

cancer, made up of 326 familial prostate cancer patients and 499 cases of sporadic prostate cancer, all of the latter group comprising of organ confined disease. Control group came from men of a similar age from the local population (Rochester Epidemiology Project), who were invited to enrol and subsequently had a careful history, physical examination and if necessary a TRUS biopsy. Once prostate cancer had been ruled out, they were incorporated as a control group. In total there were 510 such men. This study also linked $\mathrm{R}_{462} \mathrm{Q}$ status with hereditary prostate cancer and in such men disease was associated with an earlier age of onset. Like Rokman's work, this study also failed to demonstrate a correlation between the $D_{541} E$ mutation and prostate cancer risk.

Wiklund's series came from patients registered on Cancer Prostate, a Swedish nationwide database of prostate cancer patients younger than 79 diagnosed between July $1^{\text {st }} 2001$ and $30^{\text {th }}$ September 2002. Patients were invited to take part in the study and a blood sample for analysis was taken. In total, 1636 prostate cancer patients with a full spectrum of disease from early to advanced were included. Control samples were matched to similar people from the Swedish Population registry, who were invited to take part. This involved filling a questionnaire and giving a blood sample. In total 801 controls were analysed. No significant association between $\mathrm{R}_{462} \mathrm{Q}$ status and prostate cancer risk was demonstrated in this study. It did reveal a significant link $(p=0.03)$ between familial 
prostate cancer risk and $\mathrm{D}_{541} \mathrm{E}$ mutation, however no link between this variant and either age at diagnosis or tumour aggressiveness was found.

Maier's patients were recruited from the Prostate Cancer Genetics Project. This is a database made up of men from predominately from the South of Germany, the majority of whom would have undergone radical prostatectomies. Patients are encouraged to enrol in this study by their urologist and there are no selection criteria. At risk families are identified by interview of the patient. There were a total of 303 of such patients. 227 sporadic cases were also sequenced as well as 207 control samples. These samples came from healthy, elderly men with no history of prostate cancer and negative DRE and/or normal PSA levels. $\mathrm{D}_{541} \mathrm{E}$ or $\mathrm{R}_{462} \mathrm{Q}$ failed to demonstrate any significant association with prostate cancer in this study.

Noonan-Wheeler's study originated in Missouri, USA. It examined RNase $\mathrm{L}$ in men with aggressive, metastatic cancer and healthy controls. Patients were recruited from the outpatient department and were required to have a PSA over $50 \mathrm{ng} / \mathrm{ml}$ or radiological/pathological evidence of metastatic disease. The control group consisted of men older than 75 with normal PSA levels and rectal examination with no background of prostate cancer. There were a total of 150 patients and 171 controls examined. It was shown that $\mathrm{D}_{541} \mathrm{E}$ was over-represented $(\mathrm{p}=0.045)$ in patients with metastatic disease, and concluded that such patients were at an increased risk for sporadic, metastatic disease $(\mathrm{OR}=1.68)$.

Nakazato's study came from Japan and examined RNase L in familial prostate cancer cases and healthy controls. It comprised 101 patients with a positive family history of cancer (29 of whom had 3 or more affected family members) and 105 controls. Prostate cancer patients ranged in age from 40 to 88 years, encompassed organ confined and metastatic disease and had 76 men with a Gleason score of 7 or greater and the remaining 26 with a Gleason score of 6 or less. Control cases were recruited from the outpatients department and were of similar age. Patients with an elevated PSA or abnormal DRE were excluded from this group. Interestingly this study demonstrated a significant link between the wildtype DD variant and familial prostate cancer $(\mathrm{p}=0.0004$, $\mathrm{OR}=7.37$ ), possibly an observation unique to the Japanese population.

\section{Conclusion}

In conclusion, no statistically significant correlation was proven in the Irish population between Gleason score, percentage gland involvement, patient age, PSA or family history with any of the studied SNPs. In particular the SNP rs3738579 failed to highlight men with significant clinical cancer.

\section{REFERENCES}

[1] A. Rökman, T. Ikonen, E. H. Seppälä, N. Nupponen, V. Autio, N. Mononen, J. Bailey-Wilson, J. Trent, J. Carpten, M. P. Matikainen, P. A. Koivisto, T. L. Tammela, O. P. Kallioniemi and J. Schleutker, "Germline Alterations of the RNASEL Gene, a Candidate HPC1 Gene at 1q25, in Patients and Families with Prostate Cancer," The American Journal of Human Genetics, Vol. 70, No. 5, 2002, pp. 1299-1304. http://dx.doi.org/10.1086/340450

[2] J. Carpten, N. Nupponen, S. Isaacs, R. Sood, C. Robbins, J. Xu, M. Faruque, T. Moses, C. Ewing, E. Gillanders, P. $\mathrm{Hu}, \mathrm{P}$. Bujnovszky, I. Makalowska, A. Baffoe-Bonnie, D. Faith, J. Smith, D. Stephan, K. Wiley, M. Brownstein, D. Gildea, B. Kelly, R. Jenkins, G. Hostetter, M. Matikainen, J. Schleutker, K. Klinger, T. Connors, Y. Xiang, Z. Wang, A. De Marzo, N. Papadopoulos, O. P. Kallioniemi, R. Burk, D. Meyers, H. Gronberg, P. Meltzer, R. Silverman, J. Bailey-Wilson, P. Walsh, W. Isaacs and J. Trent, "Germline Mutations in the Ribonuclease L Gene in Families Showing Linkage with HPC1," Nature Genetics, Vol. 30, No. 2, 2002, pp. 181-184. http://dx.doi.org/10.1038/ng823

[3] A. Orr-Urtreger, A. Bar-Shira, D. Bercovich, N. Matarasso, U. Rozovsky, S. Rosner, S. Soloviov, G. Rennert, L. Kadouri, A. Hubert, H. Rennert and H. Matzkin, "RNASEL Mutation Screening and Association Study in Ashkenazi and Non-Ashkenazi Prostate Cancer Patients," Cancer Epidemiology, Biomarkers \& Prevention, Vol. 15, No. 3, 2006, pp. 474-479.

http://dx.doi.org/10.1158/1055-9965.EPI-05-0606

[4] Y. Xiang, Z. Wang, J. Murakami, S. Plummer, E. A. Klein, J. D. Carpten, J. M. Trent, W. B. Isaacs, G. Casey and R. H. Silverman, "Effects of RNase L Mutations Associated with Prostate Cancer on Apoptosis Induced by 2',5'-Oligoadenylates," Cancer Research, Vol. 63, No. 20, 2003, pp. 6795-6801.

[5] L. Wang, S. K. McDonnell, D. A. Elkins, S. L. Slager, E. Christensen, A. F. Marks, J. M. Cunningham, B. J. Peterson, S. J. Jacobsen, J. R. Cerhan, M. L. Blute, D. J. Schaid and S. N. Thibodeau, "No Association of Germline Alteration of MSR1 with Prostate Cancer Risk," Nature Genetics, Vol. 35, 2003, pp. 128-129. http://dx.doi.org/10.1038/ng1239

[6] G. Casey, P. J. Neville, S. J. Plummer, Y. Xiang, L. M. Krumroy, E. A. Klein, W. J. Catalona, N. Nupponen, J. D. Carpten, J. M. Trent, R. H. Silverman and J. S. Witte, "RNASEL Arg462Gln Variant Is Implicated in up to 13\% of Prostate Cancer Cases," Nature Genetics, Vol. 32, No. 4, 2002, pp. 581-583. http://dx.doi.org/10.1038/ng1021

[7] F. Wiklund, B. A. Jonsson, A. J. Brookes, L. Stromqvist, J. Adolfsson, M. Emanuelsson, H. O. Adami, K. Augustsson-Balter and H. Gronberg, "Genetic Analysis of the RNASEL Gene in Hereditary, Familial, and Sporadic Prostate Cancer," Clinical Cancer Research, Vol. 10, No. 21, 2004, pp. 7150-7156. http://dx.doi.org/10.1158/1078-0432.CCR-04-0982

[8] H. Li and B. C. Tai, "RNASEL Gene Polymorphisms and the Risk of Prostate Cancer: A Meta-Analysis," Clinical Cancer Research, Vol. 12, 2006, pp. 5713-5719. http://dx.doi.org/10.1158/1078-0432.CCR-05-2799 
[9] F. C. Noonan-Wheeler, W. Wu, K. A. Roehl, A. Klim, J. Haugen, B. K. Suarez and A. S. Kibel, "Association of Hereditary Prostate Cancer Gene Polymorphic Variants with Sporadic Aggressive Prostate Carcinoma," Prostate, Vol. 66, No. 1, 2006, pp. 49-56. http://dx.doi.org/10.1002/pros.20320

[10] H. Nakazato, K. Suzuki, H. Matsui, N. Ohtake, S. Nakata and H. Yamanaka, "Role of Genetic Polymorphisms of the RNASEL Gene on Familial Prostate Cancer Risk in a Japanese Population," British Journal of Cancer, Vol. 89, No. 4, 2003, pp. 691-696. http://dx.doi.org/10.1038/sj.bjc.6601075

[11] C. Maier, J. Haeusler, K. Herkommer, Z. Vesovic, J. Hoegel, W. Vogel and T. Paiss, "Mutation Screening and Association Study of RNASEL as a Prostate Cancer Susceptibility Gene," British Journal of Cancer, Vol. 92, 2005, pp. 1159-1164. http://dx.doi.org/10.1038/sj.bjc.6602401

[12] B. E. Madsen, E. M. Ramos, M. Boulard, K. Duda, J. Overgaard, M. Nordsmark, C. Wiuf and L. L. Hansen, "Germline Mutation in RNASEL Predicts Increased Risk of Head and Neck, Uterine Cervix and Breast Cancer," PLoS One, Vol. 3, No. 6, 2008, Article ID: e2492. http://dx.doi.org/10.1371/journal.pone.0002492

[13] S. Nair and M. R. Pillai, "Human Papillomavirus and Disease Mechanisms: Relevance to Oral and Cervical Cancers," Oral Diseases, Vol. 11, 2005, pp. 350-359. http://dx.doi.org/10.1111/j.1601-0825.2005.01127.x

[14] A. Leodolter, M. Naumann and P. Malfertheiner, "Prevention of Gastric Cancer by Helicobacter pylori Eradication," Digestive Diseases, Vol. 22, 2004, pp. 313-319. http://dx.doi.org/10.1159/000083592

[15] M. A. Epstein, B. G. Achong and Y. M. Barr, "Virus Particles in Cultured Lymphoblasts from Burkitt's Lymphoma," Lancet, Vol. 15, 1964, pp. 702-703. http://dx.doi.org/10.1016/S0140-6736(64)91524-7

[16] J. E. McGrory, D. J. Pritchard, K. K. Unni, D. Ilstrup and C. M. Rowland, "Malignant Lesions Arising in Chronic Osteomyelitis," Clinical Orthopaedics and Related Research, Vol. 362, 1999, pp. 181-189. http://dx.doi.org/10.1097/00003086-199905000-00027

[17] L. K. Dennis and D. V. Dawson, "Meta-Analysis of Measures of Sexual Activity and Prostate Cancer," Epidemiology, Vol. 13, 2002, pp. 72-79. http://dx.doi.org/10.1097/00001648-200201000-00012

[18] R. B. Hayes, L. M. Pottern, H. Strickler, C. Rabkin, V. Pope, G. M. Swanson, R. S. Greenberg, J. B. Schoenberg, J. Liff, A. G. Schwartz, R. N. Hoover and J. F. Fraumeni Jr., "Sexual Behaviour, STDs and Risks for Prostate Cancer," British Journal of Cancer, Vol. 82, 2000, pp. 718725. http://dx.doi.org/10.1054/bjoc.1999.0986

[19] M. L. Taylor, A. G. Mainous 3rd and B. J. Wells, "Prostate Cancer and Sexually Transmitted Diseases: A MetaAnalysis," Family Medicine Journal, Vol. 37, 2005, pp. 506-512.

[20] A. V. Sarma, J. C. McLaughlin, L. P. Wallner, R. L. Dunn, K. A. Cooney, D. Schottenfeld, J. E. Montie and J. T. Wei, "Sexual Behavior, Sexually Transmitted Diseases and Prostatitis: The Risk of Prostate Cancer in Black Men," Journal of Urology, Vol. 176, No. 3, 2006, pp. 1108-1113. http://dx.doi.org/10.1016/j.juro.2006.04.075 